\title{
Finding a Partner With the International Confederation of Midwives Provided the Investment Required to Launch in January 2011
}

After 7 years, Kerri, Soo, and I are stepping down from editing the International Journal of Childbirth. For me, the journal's gestation started 3 years before that when Soo and I believed there was a need for a multidisciplinary, pan-global childbirth journal. At the time, there were only two other similar publications in existence, and one of those was specifically focused on midwifery. It took us 3 years to find a publisher, so we are greatly indebted to Springer Publishing Company, who shared our vision for a truly international publication, even though their interests at the time were largely concentrated on North America.

We had assembled an impressive editorial board, who are largely still with us, and Kerri, Soo, and I would like to sincerely thank them all for their outstanding contribution over the years since. At first, our list of reviewers was small, so the workload was substantial, but now we have many reviewers from across the world to choose from. Many have previously published with us, and we are particularly pleased that they cover the spectrum of high- to-lowincome countries.

Over the years we have deliberately sought out contributions from authors in lower income countries, so typically our issues are very international in flavor. This is something we are particularly proud of. Indeed, we believe that the $I J C$ was ahead of the curve of other similar journals in this respect. Our link with the International Confederation of Midwives (ICM) has facilitated this focus.

As we look back over our time at the journal, there are regrets, especially at the slowness of achieving medical indexing and acquiring an Impact Factor (now within sight, hopefully for 2019). This contributed to a parting of ways with the ICM at the end of last year. It seems clichéd to say that maternity care internationally is facing significant challenges as, during the life of this journal, "t'was ever thus." But, as a parting reflection, we believe the following issues are key to women's and family health over the next decade.

Gender equality, which covers human rights, challenging disrespect, abuse, and misogyny, have been foregrounded internationally over the past 12 months. Some of the issues that have come to the surface suggest "pushback" in the gains of second-wave feminism. These play out in maternity care when it is underfunded and when preventable mortality remains alarmingly high. Gendered effects are manifest in maternity care wherever and whenever women's agency is undermined. All stakeholders need to remain vigilant regarding this issue.

The struggle to move beyond political rhetoric of personalized or individualized maternity care in the face of neoliberal consumerist forces that supervalue riskbased thinking and technological solutions is evident daily in exchanges on social media, in committees, and in clinical and interpersonal encounters, around the world. It is probably the task of our generation to try to authentically balance safety and personalized, respectful care and interpersonal relationships, so that we can achieve a "both-and" solution that really addresses the very real issue of "too little too late, too much too soon" maternity care globally. This is crucial not only for optimal outcomes for mothers, babies, and families but also in terms of ensuring sustainable maternity care into the future.

Indeed, there are signs that the conversation is changing about how pregnancy, birth, and the postnatal period should be understood and supported. We have two new World Health Organization (WHO) guidelines that have integrated the views of women and providers into their recommendations. Both frame pregnancy and birth as positive experiences. Notions of compassion are beginning to surface as a real basis for change in a range of areas, including health care. Realization that health care must be sustainable has led to a serious 
consideration of reducing overuse of intervention in health care in general, along with a growing focus on the need to ensure that all citizens receive the care they need, when they need it. The Every Woman, Every Child initiative is taking on this challenge for women, children, and families globally.

There is still a lot to do and to say, and we believe that the new incarnation of the IJC will provide an excellent place for authors to do and to say it. We wish the new editor Michelle Murray and the future editorial board all the very best in this endeavor. We are very grateful to Springer Publishing Company for continuing to provide the opportunity for those of any disciplinary background, or none, to contribute to ensuring optimal maternity outcomes for mothers, babies, families, and communities into the future.

Denis Walsh

Department of Academic Division of Midwifery, University of Nottingham, United Kingdom

Kerri D. Schuiling

Division of Academic Affairs Northern Michigan University, Michigan, United States

Soo Downe

School of Health University of Central Lancashire, England, United Kingdom 